\title{
Expression of the ubiquitin-proteasome pathway and muscle loss in experimental cancer cachexia
}

\author{
J Khal', SM Wyke', ST Russell', AV Hine' and MJ Tisdale*,I \\ 'Pharmaceutical Sciences Research Institute, Aston University, Birmingham B4 7ET, UK
}

Muscle protein degradation is thought to play a major role in muscle atrophy in cancer cachexia. To investigate the importance of the ubiquitin-proteasome pathway, which has been suggested to be the main degradative pathway mediating progressive protein loss in cachexia, the expression of mRNA for proteasome subunits $C 2$ and $C 5$ as well as the ubiquitin-conjugating enzyme, E2 ${ }_{14 k}$, has been determined in gastrocnemius and pectoral muscles of mice bearing the MACI6 adenocarcinoma, using competitive quantitative reverse transcriptase polymerase chain reaction. Protein levels of proteasome subunits and E2/4k were determined by immunoblotting, to ensure changes in mRNA were reflected in changes in protein expression. Muscle weights correlated linearly with weight loss during the course of the study. There was a good correlation between expression of C2 and E2,4k mRNA and protein levels in gastrocnemius muscle with increases of 6-8-fold for C2 and two-fold for E2 $14 \mathrm{k}$ between 12 and $20 \%$ weight loss, followed by a decrease in expression at weight losses of $25-27 \%$, although loss of muscle protein continued. In contrast, expression of C5 mRNA only increased two-fold and was elevated similarly at all weight losses between 7.5 and $27 \%$. Both proteasome functional activity, and proteasome-specific tyrosine release as a measure of total protein degradation was also maximal at $18-20 \%$ weight loss and decreased at higher weight loss. Proteasome expression in pectoral muscle followed a different pattern with increases in $\mathrm{C} 2$ and C5 and E2 ${ }_{14 \mathrm{k}}$ mRNA only being seen at weight losses above 17\%, although muscle loss increased progressively with increasing weight loss. These results suggest that activation of the ubiquitin-proteasome pathway plays a major role in protein loss in gastrocnemius muscle, up to $20 \%$ weight loss, but that other factors such as depression in protein synthesis may play a more important role at higher weight loss.

British Journal of Cancer (2005) 93, 774-780. doi: I 0.1038/sj.bjc.6602780 www.bjcancer.com

Published online 6 September 2005

(c) 2005 Cancer Research UK

Keywords: cachexia; protein degradation; ubiquitin-proteasome proteolysis; gastrocnemius muscle

Loss of skeletal muscle is a prominent feature of cancer cachexia, resulting in weakness, immobility and finally death. Body composition analysis of lung cancer patients who had lost $30 \%$ of their body weight revealed a $75 \%$ reduction in skeletal muscle mass, while visceral proteins were preserved (Fearon, 1992). Loss of skeletal muscle protein is thought to arise from a suppression of protein synthesis (Emery et al, 1984) and/or an increase in protein breakdown and oxidation of amino acids (O'Keefe et al, 1990).

A number of experimental animal tumours have been developed to study the mechanism of muscle wasting in cachexia. In the murine MAC16 colon adenocarcinoma model, weight loss occurs with small tumour burden (less than $0.1 \%$ of host weight), and without a reduction of food and water intake (Beck and Tisdale, 1987), allowing a study of the metabolic components of cachexia. As in cancer patients, the major components of body weight loss in the MAC16 model are adipose tissue and skeletal muscle mass. Loss of skeletal muscle mass arises from a reduction (by 60\%) in protein synthesis and an increase (three-fold) in protein degradation (Beck et al, 1991). As was found in a rat model of cancer cachexia (Baracos et al, 1995; Llovera et al, 1997), the major contribution to the loss of muscle mass in mice bearing the MAC16 tumour appears to arise from an upregulation of the ATP-

*Correspondence: MJ Tisdale; E-mail: m.j.tisdale@aston.ac.uk

Revised 10 August 2005; accepted 10 August 2005; published online 6 September 2005 ubiquitin-dependent proteolytic pathway (Lorite et al, 1998), as reflected by increased levels of ubiquitin-conjugated proteins and increased mRNA levels for the $14 \mathrm{kDa}$ ubiquitin carrier protein, E2 and the $\mathrm{C} 9$ proteasome subunit in gastrocnemius muscle. However, as with other studies in animals this was only measured after weight loss had developed, and there have been no measurements of the expression of the major components of the ubiquitin-proteasome pathway at different extents of weight loss, or a comparison between different muscle types to understand if this pathway totally explains protein degradation. However, a study in gastric cancer patients showed an increase in expression of ubiquitin mRNA and proteasome activity compared with controls, and proteasome activity correlated both with stage of disease and weight loss (Bossola et al, 2003).

The purpose of the present study was to measure changes in expression of the key regulatory components of the ubiquitinproteasome proteolytic pathway in skeletal muscle with the development of cachexia in the MAC16 model. Protein degradation in this model has been shown to increase progressively with increasing weight loss between 15 and $30 \%$, up to a maximum increase of $240 \%$ at a weight loss of $30 \%$ (Smith and Tisdale, 1993a). Expression of mRNA for E2, and the proteasome subunits C2 and C5, representing $\alpha$ and $\beta$ subunits of the proteasome respectively, have been determined in gastrocnemius and pectoral muscle by quantitative RT - PCR as a measure of the ubiquitinproteasome pathway. These are considered to be representative of 
proteasome structural and catalytic subunits indicative of proteasome expression. Previous studies (Lorite et al, 2001; Whitehouse et al, 2001) have shown that subunits of the $19 \mathrm{~S}$ regulator change in concert with the proteasome $\alpha$-subunit. As a measure of ubiquitin conjugation mRNA levels for E2 ${ }_{14 k}$ have been determined, which was originally suggested to be rate-limiting for ubiquitin conjugation during starvation (Wing and Banville, 1994), although studies in $\mathrm{E} 22_{14 \mathrm{k}}$ knockout mice suggest that it is nonessential (Adegoke et al, 2002). However, recent data suggest that the ubiquitin-protein ligases (E3), muscle ring-finger 1 (MURF1); (Bodine et al, 2001) and muscle atrophy $\mathrm{F}$ box (MAFbx)/atrogin-1 (Gomes et al, 2001), may be the rate-limiting step in various conditions of muscle atrophy including cachexia.

In this study, the expression of some components of the ubiquitin-proteasome pathway has been monitored with increasing weight loss in gastrocnemius and pectoral muscle of mice bearing the MAC16 tumour, since some reports (Khal et al, 2005) suggest that the expression of this pathway in the skeletal muscle of cancer patients decreases at weight losses greater than $20 \%$. Measurements of protein levels of proteasome $\alpha$-subunits and $\mathrm{E} 2{ }_{14 \mathrm{k}}$ have also been determined by immunoblotting to ensure that changes in mRNA are reflected in changes in protein expression.

\section{MATERIALS AND METHODS}

\section{Materials}

Mouse monoclonal antibody to $20 \mathrm{~S}$ proteasome subunits $\alpha 1,2$, 3, 5 and 7 (clone MCP231) was purchased from Affinity Research Products (Exeter, UK). Rabbit polyclonal antisera to E2 ${ }_{14 \mathrm{k}}$ was a gift from Dr Simon Wing (McGill University, Montreal, Canada). The antibody detected E2 $14 \mathrm{k}$ as a $M_{\mathrm{r}} 17 \mathrm{kDa}$ band (Rajapurohitam et al, 1999). Goat polyclonal antiserum to MURF3 (E3) and peroxidase-conjugated rabbit polyclonal antisera to goat IgG were purchased from Abcam Ltd (Cambridge, UK). Mouse monoclonal anti-PIF antibody was prepared as previously (Todorov et al, 1996). Peroxidase-conjugated goat anti-rabbit and rabbit antimouse secondary antibodies were from Dako Ltd (Cambridge, UK).

Wizard $^{\mathrm{TM}}$ mini or maxi preps, used to prepare plasmid DNA from overnight cultures of bacterial clones, were obtained from Promega (Southampton, UK), as were the T7 RNA polymerase kit, RNAsin inhibitor, reverse transcriptase, reverse transcription buffer and PCR grade magnesium chloride. Taq polymerase and Hybond C were from Amersham Biosciences UK Ltd (Bucks, UK), TRI reagent for RNA isolation was purchased from Sigma-Aldrich Co-Ltd (Dorset, UK), while the oligonucleotide primers were from MWG Biotech (Ebersberg, Germany). RNA storage buffer was purchased from Ambion Ltd (Cambridgeshire, UK) and PCR buffer was from Roche, Switzerland.

\section{Animals}

All animal experiments have been carried out with ethical committee approval. The ethical guidelines that were followed met the standards required by the UKCCR guidelines (Workman et al, 1998).

Pure strain NMRI mice were obtained from our own inbred colony and were fed a rat and mouse breeding diet (Special Diet Services, Witham, UK). Fragments of the MAC16 colon adenocarcinoma, excised from donor animals with established weight loss, were implanted into the flanks of NMRI mice by means of a trocar, as described (Beck and Tisdale, 1987). Animals started to lose weight approximately 10-12 days after transplantation. Animals were terminated at various extents of weight loss, and both gastrocnemius and pectoral muscles were removed, and immediately frozen in liquid nitrogen, and stored at $-70^{\circ} \mathrm{C}$ before further analysis.

\section{Measurement of protein degradation ex vivo}

Gastrocnemius muscles were excised from mice bearing the MAC16 tumour, and with varying extents of weight loss, and preincubated for $45 \mathrm{~min}$ in $3 \mathrm{ml}$ oxygenated (95\% oxygen $/ 5 \%$ carbon dioxide) Krebs-Henseleit bicarbonate buffer, $\mathrm{pH}$ 7.4, containing $5 \mathrm{mmol}^{-1}$ glucose and $0.5 \mathrm{mmoll}^{-1}$ cycloheximide. Protein degradation was determined by the release of tyrosine (Waalkes and Udenfriend, 1957) over a $2 \mathrm{~h}$ period in the absence and presence of lactacystin $(10 \mu \mathrm{M})$. Tyrosine release, which was blocked in the presence of lactacystin, was considered to be proteasome specific.

\section{Measurement of proteasome activity}

The 'chymotrypsin-like' enzyme activity of the proteasome was measured fluorometrically as described by Orino et al (1991). Muscles were removed from animals with varying degrees of weight loss and homogenized with a teflon glass homogenizer in $20 \mathrm{~mm}$ Tris- $\mathrm{HCl}, \mathrm{pH}$ 7.5, $2 \mathrm{~mm}$ ATP, $5 \mathrm{~mm} \mathrm{MgCl}_{2}$ and $1 \mathrm{~mm}$ DTT on ice at $4{ }^{\circ} \mathrm{C}$. The homogenate was further dissociated by sonication at $4^{\circ} \mathrm{C}$, and the sonicate was then centrifuged at $18000 \mathrm{~g}$ for $10 \mathrm{~min}$, and the supernatant was used to measure enzyme activity by the release of aminomethylcoumarin (AMC) from succinyl-LLVY-AMC. The reaction was performed for $1 \mathrm{~h}$ at room temperature in $100 \mathrm{~mm}$ Tris. $\mathrm{HCl}, \mathrm{pH} 8.0$, and was terminated by the addition of $80 \mathrm{~mm}$ sodium acetate, $\mathrm{pH}$ 4.3. The fluorescence of AMC was determined with an excitation wavelength of $360 \mathrm{~nm}$ and an emission wavelength of $460 \mathrm{~nm}$. The reaction was performed in the presence and absence of the specific proteasome inhibitor lactacystin, and only lactacystin suppressible activity was considered to be proteasome specific. The activity was adjusted for the protein concentration of the sample, determined using the Bradford assay (Sigma Aldridge, Dorset, UK).

\section{Quantitative RT - PCR}

Total RNA was extracted from muscle using TRI-reagent and the RNA concentration was determined from the absorbance at $260 \mathrm{~nm}$. To quantitate the mRNA of interest, increasing amounts of competitor RNA, which differed from the mRNA of interest by containing a short deletion, were added to $250 \mathrm{ng}$ of total RNA and coamplified using RT-PCR. The amount of specific mRNA was calculated from the amount of competitor, when equal amounts of PCR product were obtained from the competitor and target RNA.

The C2 proteasome subunit mRNA was amplified using the primer pairs: $5^{\prime}$-CGCACGGAGTGCTGGTTGCAC-3' (forward) and $5^{\prime}$-GTACGAGCTGATTGAGAACGG-3' (reverse) and corresponds to positions $176-187$ and $531-552 \mathrm{bp}$. The competitor primer was designed to produce a DNA fragment containing a 76-bp deletion by producing a loop in the DNA during the PCR amplification process. The sequence of this primer was $5^{\prime}$-GTACGAGCTGATT GAGAACGGCATAACCAGCAATGAGCAGCC- $3^{\prime}$, which corresponds to the reverse complement of bases 561-552 and 435455 of the mouse $\mathrm{C} 2$ gene. The competitor product was $309 \mathrm{bp}$. The C5 proteasome mRNA was obtained from the mouse gene using the primer pairs: $5^{\prime}$-TCAACGGAGGTACTGTATTGG- $3^{\prime}$ and $5^{\prime}-$ GCATGGCACTTGCTGAGCC-3' at positions $101-121$ and $496-$ $514 \mathrm{bp}$. The competitor primer was designed $117 \mathrm{bp}$ upstream of the reverse primer producing a product $277 \mathrm{bp}$ long. The sequence of this primer was $5^{\prime}$-GCATGGCACTTGCTGAGCCGCATGG CACTTGCTGAGCC- $3^{\prime}$, which corresponds to the reverse complement of bases 496-514 and 358-377 of the mouse C5 gene. The $\mathrm{E} 2$ 14k $_{\mathrm{k}}$ competitor was obtained from the rat gene using the primer pairs: $5^{\prime}$-CTCATGCGGGATTTCAAGCG- $3^{\prime}$ and 5'-CTCTTCTCA 
TACTCCCGTTTGCAT- $3^{\prime}$. The competitor primer contained a $111 \mathrm{bp}$ deletion and the sequence was $5^{\prime}$-CTCTTCTCATACTCCC GTTGCATCGCTTCTGCAGGATGTC, which corresponds to the reverse complement of bases $443-468$ and 312-321 of the rat gene. The competitor DNAs were blunt ended and then ligated into a pET30a vector, which had been blunt-end cut with SmaI restriction enzyme. The ligated vector was used to transform DH5 $\alpha$ competent cells. Plasmid DNA was prepared from PCR positive clones using Wizard-mini-prep. Competitor RNA was produced using T7 RNA polymerase kit, and quantitated using the optical density at $260 \mathrm{~nm}$. Six serial two-fold dilutions were prepared containing known concentrations of competitor. The particular dilutions used were selected to span the selected concentration of C2, C5 and $\mathrm{E} 2{ }_{14 \mathrm{k}}$ in the sample.

To synthesise the cDNA template, a mixture consisting of $250 \mathrm{ng}$ target RNA, the particular dilution of the competitor RNA and $0.5 \mu \mathrm{g}$ of random hexamer was incubated at $70^{\circ} \mathrm{C}$ for $5 \mathrm{~min}$ in a thermal cycler (Genetic Research, Instrumentation Ltd, Essex, UK) and then chilled on ice before the addition of $2.5 \mu \mathrm{l} 5 \times$ reverse transcription buffer, $3 \mu \mathrm{l}$ of $10 \mathrm{~mm}$ each of dATP, dGTP, dCTP, dTTP, 5 units of RNAsin inhibitor and 1 unit reverse transcriptase in a total volume of $12.5 \mu \mathrm{l}$. Incubation was at $37^{\circ} \mathrm{C}$ for $1 \mathrm{~h}$. For the amplification of the cDNA by PCR, $50 \mu \mathrm{l}$ of PCR mix was added to each tube. The PCR mixture contained $1 \times$ PCR buffer (without magnesium) together with $3 \mathrm{~mm} \mathrm{MgCl}_{2}$ (E2), $3.5 \mathrm{mM} \mathrm{MgCl}_{2}$ (C5) and $2.5 \mathrm{mM} \mathrm{MgCl}_{2}$ (C2) together with $1 \mathrm{U}$ Taq polymerase. For the E2 gene 10 pmol of each of the primers $5^{\prime}$-CTCATGCGGGATTT CAAGCG- $3^{\prime}$ and $5^{\prime}$-CTCTTCTCATACTCCCGTTTG- $3^{\prime}$ were used, while for the $\mathrm{C} 5$ gene $10 \mathrm{pmol}$ of each of the primers $5^{\prime}$ TCAACGGAGGTACTGTATTGG- $3^{\prime}$ and $5^{\prime}$-GCATGGCACTTGCT GAGCC- $3^{\prime}$ were used. For the $\mathrm{C} 2$ gene, $20 \mathrm{pmol}$ of each of the primers $5^{\prime}$-CGCACGCAGTGCTGGTTGCAC- $3^{\prime}$ and $5^{\prime}$-GTACGAG CTGATTGAGAACGG-3' were used. The temperature-cycling profile for amplification was as follows: $95^{\circ} \mathrm{C}$ for $2 \mathrm{~min}$ for one cycle followed by $95^{\circ} \mathrm{C}$ for $30 \mathrm{~s}, 58^{\circ} \mathrm{C}$ annealing for $1 \mathrm{~min}$ and $72^{\circ} \mathrm{C}$ extension for $1 \mathrm{~min}$ for 30 cycles. Control reactions containing all components except reverse transcriptase and another without template were carried out alongside each experiment to show that the RNA (both target and competitor) had no DNA contamination, while the second control showed that there was no contamination in the PCR mixture. Coamplification of E2 target and competitor produced DNA fragments of 395 and 284-bp, respectively; C2 target and competitor produced 385 and 309-bp fragments and C5 target and competitor produced 414 and 297-bp fragments, respectively.

For analysis of results, $15 \mu \mathrm{l}$ of PCR products were separated on a $2 \%\left(\mathrm{w} \mathrm{v}^{-1}\right)$ agarose gel containing ethidium bromide. The gel images were visualised on a UV transilluminator and photographed. The intensity of the bands was quantitated using a Phoretix photo-imager programme. The volumes of the competitor and target bands were plotted against the known serial dilutions of the competitor used in the experiment. The amount of the sample RNA corresponds to the amount of competitor when the ratio of competitor to target is 1.0 .

\section{Western blot analysis}

Cytosolic protein (5 $\mu \mathrm{g}$ for E2 and 20S proteasome $\alpha$-subunits) was resolved on $10 \%$ sodium dodecylsulphate, polyacrylamide gels. Proteins were then transferred to nitrocellulose membranes (Hybond C), which had been blocked with 5\% Marvel in Tris buffered saline (TBS) at $4{ }^{\circ} \mathrm{C}$ overnight. The primary and secondary antibodies, peroxidase conjugated either rabbit anti-goat, goat anti-rabbit or rabbit anti-mouse IgG, were used at a $1: 1500$ dilution. Incubation was for $1 \mathrm{~h}$ at room temperature and development was by enhanced chemiluminescence (ECL) (Amersham). Blots were scanned by a densitometer to quantitate differences, and a parallel gel was stained by coomassie blue stain to ensure equal loading. The intensity of bands was quantitated using 'Phoretix 1D Advanced' software as above.

\section{Statistical analysis}

Results were expressed as means \pm s.e.m. of three separate determinations on different animals. Differences were determined by one-way analysis of variance (ANOVA) followed by TukeyKramer multiple comparison test. $P$-values less than 0.05 were considered to be significant.

\section{RESULTS}

The effect of increasing weight loss on expression of C2 and C5 mRNA as well as $20 \mathrm{~S}$ proteasome $\alpha$-subunit protein levels, detected by Western blotting, and gastrocnemius muscle weights of mice bearing the MAC16 tumour is shown in Figure 1. Although the monoclonal antibody to the $20 \mathrm{~S}$ proteasome reacts with six different $\alpha$-type subunits, only three bands were apparent at approximate $M_{\mathrm{r}} 29,32$ and $35 \mathrm{kDa}$ (Whitehouse et al, 2001) (Figure 1A). There was a good correlation between expression of $\mathrm{C} 2$ mRNA (Figure 1C) and proteasome protein (Figure 1B), with a 6-8-fold increase in C2 mRNA with increasing weight loss from $12 \%$, reaching a maximum at $15-20 \%$ weight loss. Although C2 mRNA expression at $25-27 \%$ weight loss was significantly enhanced above that found in animals without weight loss (Figure 1C), it was significantly decreased $(P<0.05)$ compared with animals exhibiting $20 \%$ weight loss. In contrast, expression of C5 mRNA was significantly increased (by two-fold) at all weight losses (Figure 1D), with no significant difference between animals with $7.5 \%$ weight loss and those with $27 \%$ weight loss. Gastrocnemius muscle weight was directly proportional to total body weight loss, showing progressive loss of skeletal muscle as the cachexia progresses (Figure 1E). Proteasome functional activity in gastrocnemius muscle as determined by the 'chymotrypsin-like' enzyme activity, the dominant catalytic activity of the $\beta$-subunits of the proteasome, was found to follow a similar change with weight loss as expression of protein and mRNA of proteasome $\alpha$ subunits, with an initial increase with weight loss up to $20 \%$ followed by a decrease at higher weight loss (Figure 1F).

The effect of progressive weight loss on the expression of the ubiquitin conjugating protein E2 in gastrocnemius muscle followed a similar pattern to that observed with proteasome $\alpha$-subunits (Figure 2). Thus, expression of E2 mRNA was increased two-fold in gastrocnemius muscle of mice with $12 \%$ weight loss and remained elevated up to $20 \%$ weight loss (Figure 2C). The expression of E2 mRNA in gastrocnemius muscle of mice with 25 and $27 \%$ weight loss was not significantly different from that in mice without weight loss (Figure 2C). The expression of E2 $2_{14 \mathrm{k}}$ protein, detected by Western blotting, followed a similar pattern reaching maximal expression at $15-17 \%$ weight loss (Figure $2 \mathrm{~A}$, B). Proteasome-specific protein degradation in gastrocnemius muscle, determined by the release of tyrosine in the presence of the specific proteasome inhibitor lactacystin (Fenteany and Schreiber, 1998), also peaked between 17 and 20\% weight loss and then decreased at higher weight loss (Figure 2D). These results suggest that the ubiquitin-proteasome proteolytic pathway plays a minor role in the degradation of proteins in gastrocnemius muscle at weight loss greater than $20 \%$.

Proteasome functional activity in pectoral muscle followed a similar pattern to that found in gastrocnemius muscle (Figure $3 \mathrm{~A}$ ) peaking at weight loss between 18 and $22 \%$. Expression of mRNA for the catalytic $\beta$ subunit (C5) also peaked at weight loss between 17 and $25 \%$ with a decrease at higher weight loss (Figure $3 \mathrm{~B}$ ). However, expression of mRNA for the proteasome $\alpha$-subunit C2 (Figure 3C) as well as protein expression of $\alpha$-subunits (Figure 3D and $\mathrm{E}$ ) increased with increasing weight loss with no evidence for a 

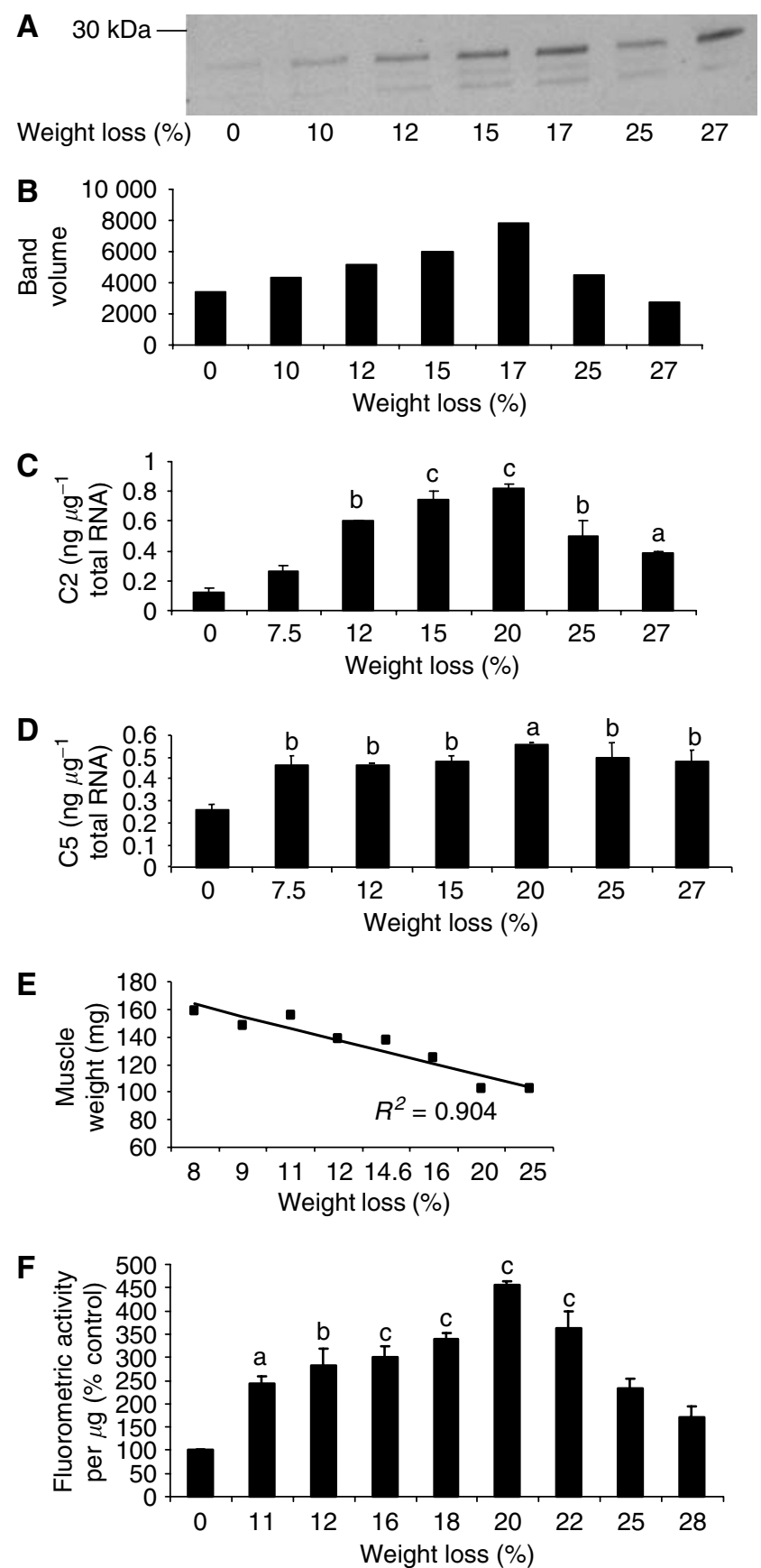

Figure I (A) Expression of 205 proteasome $\alpha$-subunits in soluble fractions of gastrocnemius muscles of mice bearing the MAC I 6 tumour and with different extents of weight loss, as detected by immunoblotting. (B) Densitometric analysis of band intensities in $(\mathbf{A})$ reported in arbitary units. (C) Expression of C2 mRNA and (D) expression of C5 mRNA in gastrocnemius muscle from mice with different extents of weight loss. Differences from animals without weight loss are expressed as a, $P<0.05$, b, $P<0.01$ and $c,<0.001$. (E) Relationship between weight of gastrocnemius muscle and percentage weight loss. (F) Proteasome proteolytic activity, as measured by the 'chymotrypsin-like' enzyme activity, in gastrocnemius muscle of mice with different extents of weight loss. The symbols for significance are the same as in (D).

maximum. As with gastrocnemius muscle there was a linear correlation between pectoral muscle weight and total body weight loss (Figure 3F). Expression of E2 mRNA was little changed with increase in weight loss in pectoral muscle (Figure 4), with a
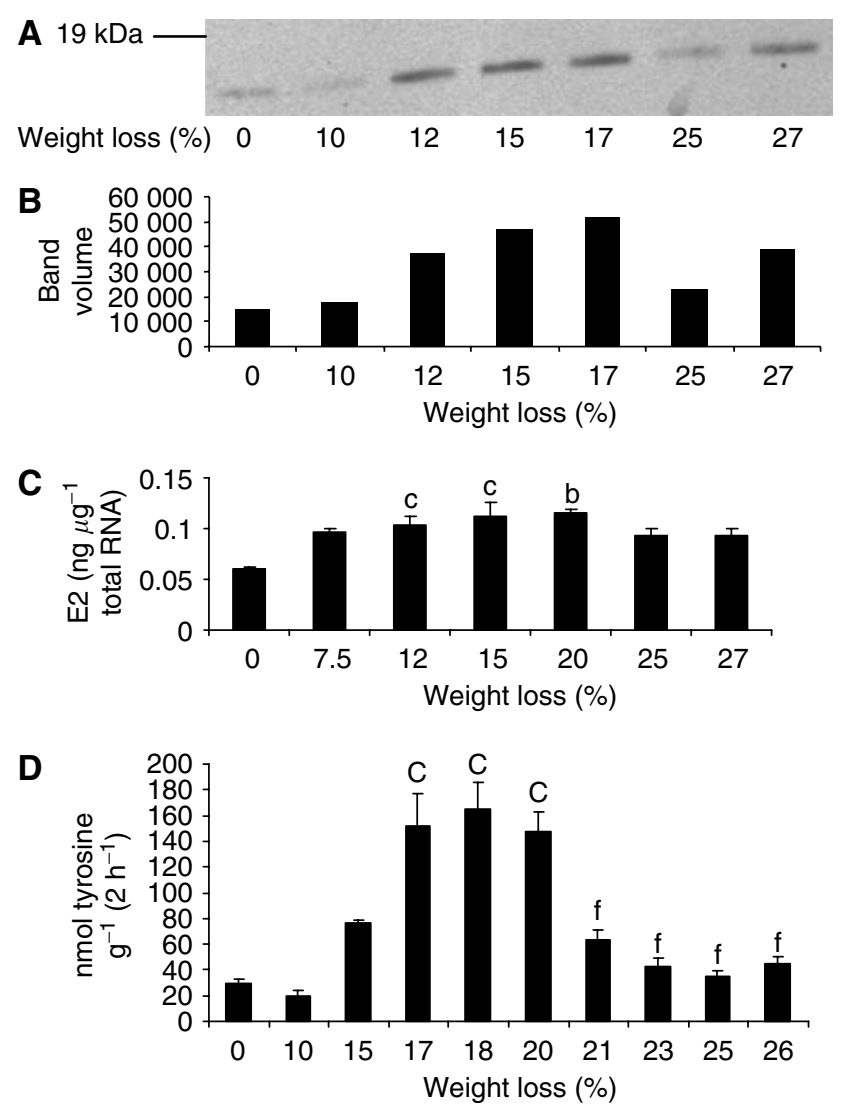

Figure 2 (A) Expression of E2/4k in soluble extracts of gastrocnemius muscles from mice bearing the MACI 6 tumour and with different extents of weight loss, as detected by immunoblotting. (B) Densitometric analysis of band intensities in $(\mathbf{A})$ reported in arbitary units. (C) Expression of E2 mRNA in gastrocnemius muscle from mice with different extends of weight loss. (D) Total protein degradation, as measured by tyrosine release, in gastrocnemius muscle of mice with different extents of weight loss. The figures represent protein degradation inhibited by lactacystin $(10 \mu \mathrm{M})$. Differences from animals without weight loss are expressed as $b, P<0.0$ I or $c, P<0.001$

significant increase in expression only being seen in animals with $27 \%$ weight loss. This suggests that E2 may not be a rate-limiting step in proteasome proteolysis in this muscle.

\section{DISCUSSION}

Skeletal muscle contains multiple proteolytic pathways for intracellular protein catabolism. Of these, the lysosomal system, including cathepsins $\mathrm{B}, \mathrm{D}$ and $\mathrm{H}$, is mainly concerned with the digestion of extracellular proteins, although some cytosolic proteins are engulfed in autophagic vacuoles that fuse with lysosomes and are degraded (Dice, 1990). The cytosolic calciumactivated pathway (calpains) appears to play an important role in tissue injury, necrosis and autolysis (Lecker et al, 1999). These two processes have been suggested to contribute less than 15-20\% towards total protein breakdown in muscle (Attaix et al, 1998; Lecker et al, 1999) and do not breakdown myofibrillar proteins (Lovell et al, 1986). However, the calcium/calpain pathway has been suggested to release myofilaments from the sarcomere in an early and perhaps rate-limiting component of the catabolic response in muscle (Hasselgren and Fischer, 2001). Further catabolism of the actin and myosin released from the myofilaments is considered to occur via the ubiquitin-proteasome proteolytic pathway. 

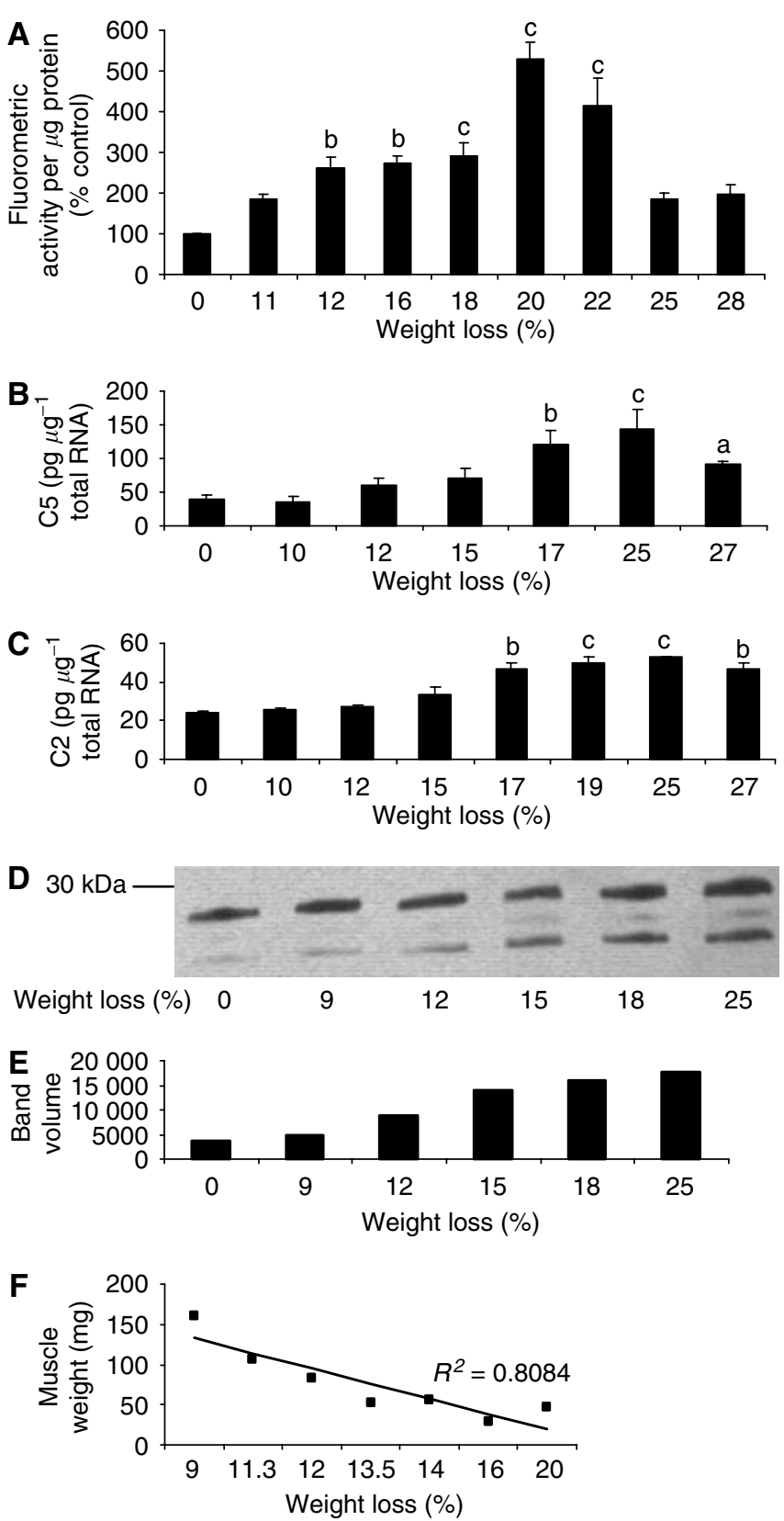

Figure 3 (A) Proteasome proteolytic activity, as measured by the 'chymotrypsin-like' enzyme activity, in pectoral muscle of mice bearing the MAC 16 tumour and with different extents of weight loss. (B) Expression of C5 mRNA and (C) expression of C2 mRNA in pectoral muscle from cachectic mice bearing the MACl6 tumour. (D) Expression of 205 proteasome $\alpha$-subunits, determined by immunoblotting, in soluble extracts of pectoral muscle from mice bearing the MACI 6 tumour and different extents of weight loss. (E) Densitometric analysis of band intensities in (D). Differences from animals without weight loss are expressed as a, $P<0.05$, b, $P<0.01$ and $c<0.001$. (F) Relationship between weight of pectoral muscle and percentage weight loss.

In this process, substrates are marked for degradation through the attachment of a polyubiquitin chain by a series of enzymatic steps mediated by the ubiquitin-activating enzyme (E1), the ubiquitin-conjugating enzyme (E2) and the ubiquitin-protein ligases (E3) (Lecker et al, 1999). The polyubiquitinated substrate then enters the proteolytic chamber of the $26 \mathrm{~S}$ proteasome, where it is unfolded and cleaved to short oligopeptides having mean lengths of 6-9 residues (Kisselev et al, 1999). The proteasome is a
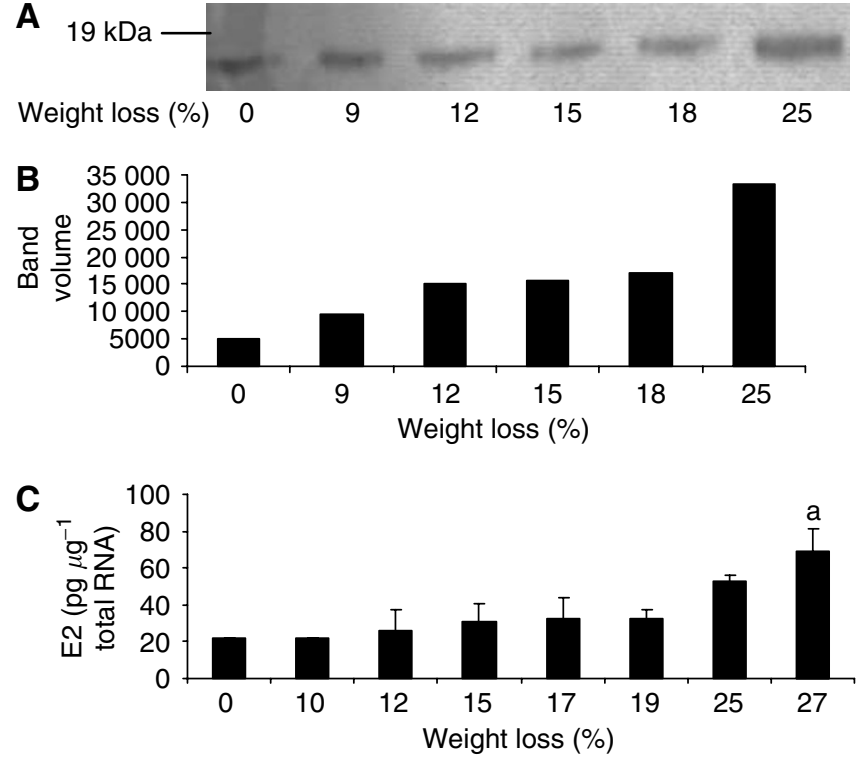

Figure 4 (A) Expression of E2 $14 k$ in soluble extracts of pectoral muscle from mice bearing the MAC 16 tumour and different extents of weight loss, detected by immunoblotting. (B) Densitometric analysis of band intensities in $(\mathbf{A})$ reported in arbitary units. (C) Expression of E2 mRNA in pectoral muscle of mice with different extents of mice loss. Differences from animals without weight loss are expressed as a, $P<0.05$.

tube-like structure appearing as a stack of four rings; two outer $\alpha$-rings and two inner $\beta$-rings in order of $\alpha \beta \beta \alpha$ (Lecker et al, 1999). Proteolytic activity is found on the $\beta$-subunits of the proteasome.

Most studies in cancer patients with weight loss of $10 \%$ or higher have suggested that the ubiquitin-proteasome pathway in skeletal muscle shows an increased expression and activity (Williams et al, 1999; Bossola et al, 2003). However, a study of lung cancer patients referred for curative resection and with a weight loss of only $2.9 \%$ showed no increase in expression of components of the ubiquitin-proteasome pathway, while mRNA levels of cathepsin B in skeletal muscle were much higher (Jagoe et al, 2002). This suggests that activation of the ubiquitin-proteasome pathway may only occur when weight loss becomes substantial, although Bossola et al (2001) reported an increase in ubiquitin mRNA in skeletal muscle of patients when the weight loss was only $5.6 \pm 4.9 \%$.

In this study, we have measured the expression of one $\alpha$ (C2) and one $\beta$-subunit (C5) of the proteasome during the progression of loss of gastrocnemius and pectoral muscle in the murine MAC16 cachexia model, as a representative of proteasome structure and function. We chose these genes since protein breakdown in cancer cachexia has been suggested to require increased gene expression of proteasome subunits (Temparis et al, 1994) and mRNA levels for proteasome subunits $\mathrm{C} 2$ and $\mathrm{C} 5$ were found to be increased in extensor digitorum longus (EDL) muscles of rats starved for 2 days, as well as in soleus muscles undergoing denervation atrophy (Medina et al, 1995). In addition, we have measured expression of mRNA for the ubiquitin-conjugating enzyme $\left(\mathrm{E} 2_{14 \mathrm{k}}\right)$. Expression of mRNA has been quantitated using RT-competitive PCR, which is based on competitive coamplification of the specific target sequence with an internal standard sharing primer recognition sites in one reaction tube (Auboeuf and Vidal, 1997). Quantitation can then be performed by comparing the PCR signals of the specific template with those obtained with known concentrations of the competitor. Protein expression has also been determined by immunoblotting, since it has been suggested that in various cells elevated concentrations of mRNA of proteasome subunits were not found to be accompanied by increased concentrations of 

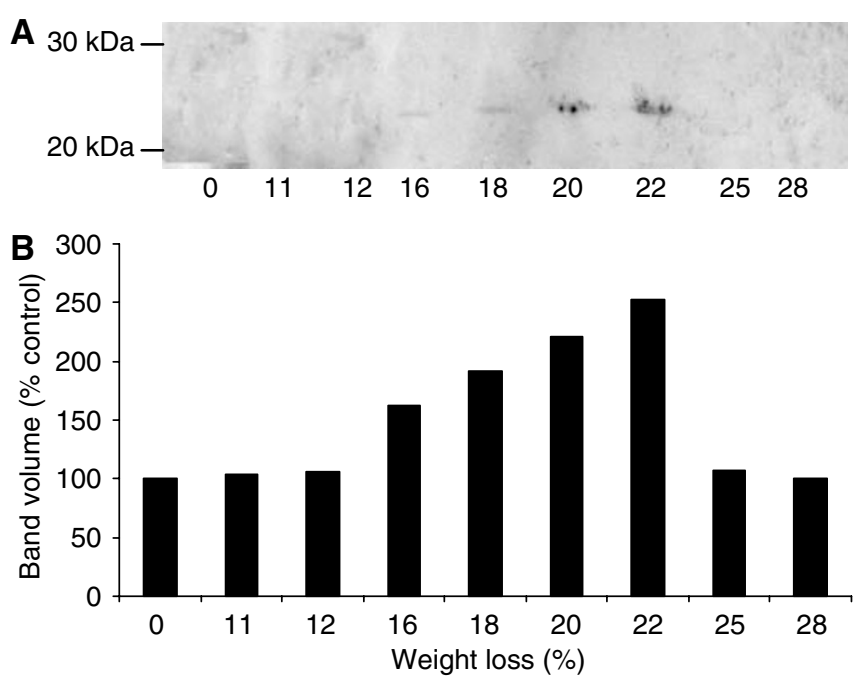

Figure 5 (A) Expression of PIF in urinary extracts of mice bearing the MACI 6 tumour. Urine $(2 \mathrm{ml})$ was treated with ammonium sulphate $(80 \%$ $\mathrm{Wv}^{-1}$ ) and stirred overnight at $4^{\circ} \mathrm{C}$. The precipitated protein was recovered by centrifugation at $3000 \mathbf{g}$ for $30 \mathrm{~min}$, dialysed against water using an Amicon filtration cell and I $5 \mu \mathrm{g}$ was used for immunoblotting using anti-PIF monoclonal antibody. (B) Densitometric analysis of the band intensities in $(\mathbf{A})$ reported in arbitary units.

proteasomes (Kanayama et al, 1991; Shimbara et al, 1992). We have also measured protein expression of E2 $14 \mathrm{k}$.

Using this approach, we have demonstrated a correlation between increases in mRNA and protein expression of proteasome $\alpha$ subunits in both gastrocnemius and pectoral muscle. We have also demonstrated a correlation between E2 mRNA and protein levels, although this was less strongly correlated with muscle weight, suggesting that it was not rate-limiting for proteasome proteolysis as might be predicted (Adegoke et al, 2002). Proteasome expression and activity in both pectoral and gastrocnemius muscles increased progressively with increasing weight loss up to about $20 \%$ followed by a decrease at higher weight loss, except for C2 mRNA in pectoralis muscle, which remained elevated. There was also a decrease in E2 expression at weight losses greater than 20\%. Proteasome specific total protein degradation in gastrocnemius muscle, as determined by tyrosine release in the presence of lactacystin, also peaked at $18-20 \%$ weight loss and then decreased. A similar rise and fall of the ubiquitin-proteasome pathway was observed in psoas muscle of alloxan-induced diabetic rabbits (Galban et al, 2001). Thus, the activity increased 3 and 5 days after diabetes induction, but fell down to control values by day 7 , and thereafter decreased below control. In pectoral muscle, both mRNA and protein for proteasome $\alpha$-subunits tended to increase with increasing weight loss, suggesting a lack of coordination between synthesis of $\alpha$ and $\beta$ subunits. We have previously shown (Smith and Tisdale, 1993a) that total body nitrogen and the nitrogen content of gastrocnemius muscle decreases with increasing weight loss in mice bearing the MAC16 tumour. The protein content of skeletal muscle is a balance between the rate of protein synthesis and the rate of degradation. Protein synthesis is depressed in muscle of weight-losing mice bearing the MAC16 tumour, and this reduction in protein synthesis may be the major factor contributing to loss of protein at weight losses greater than $20 \%$.

Using the release of tyrosine as a measure of muscle protein degradation breakdown to detect serum factors from the MAC16 tumour that increase protein degradation, activity was found to increase with increasing weight loss up to $20 \%$, and with further weight loss the activity was found to fall to a value not significantly different from that found in animals without weight loss (Smith and Tisdale, 1993b). This circulatory factor has now been isolated and identified (Todorov et al, 1996) and shown to be a sulphated glycoprotein of $M_{\mathrm{r}} 24 \mathrm{kDa}$ called proteolysis factor (PIF), which induces an increased expression of both proteasome subunits and E2 in gastrocnemius muscle (Lorite et al, 2001). Proteolysis factor has been shown to be responsible for the loss of skeletal muscle in cachectic mice (Lorite et al, 1998). Using Western blotting to detect urinary PIF in mice bearing the MAC16 tumour, excretion levels were found to be maximal at weight loss between 20 and $22 \%$ (Figure 5). This pattern parallels changes in expression of proteasome subunits in both gastrocnemius and pectoral muscle suggesting that PIF is responsible for the upregulation of the ubiquitin-proteasome pathway. Expression of C2 and C5 mRNA in rectus abdominis muscle of cachectic cancer patients was also found to be maximal at a weight loss of $12-19 \%$ (Khal et al, 2005). The rate of muscle catabolism, as measured by phenylalanine release, in a rat model of cachexia was also highest at small tumour burdens and decreased as the tumour grew larger (de Blaauv et al, 1997). This appeared to be caused by the loss of capacity of the tumour to further break down muscle. The reason for this is not known, but it may be that as the tumour grows and becomes necrotic cells capable of synthesizing PIF are lost. Alternatively, the tumour microenvironment may not be conducive to the synthesis of a highly glycosylated peptide.

The mechanism for the loss of protein in gastrocnemius muscle at weight losses greater than $20 \%$ requires further investigation, but the lack of bioactivity of serum from mice bearing the MAC16 tumour at weight losses of 20-25\% (Smith and Tisdale, 1993b) suggests that a circulatory factor is not responsible for the protein degradation, and the present results suggest that the ubiquitinproteasome pathway alone cannot account for the high level of protein breakdown. This suggests that depression of protein synthesis may be more important than an increase in protein degradation at high weight loss.

\section{ACKNOWLEDGEMENTS}

This work was supported by the Lustgarten Foundation for Pancreatic Cancer Research. We thank Mr M Wynter and Mr W Fleary for tumour transplantation and animal care.

\section{REFERENCES}

Adegoke OAJ, Bedard N, Roest HP, Wing SS (2002) Ubiquitin-conjugating enzyme $\mathrm{E} 2_{14 \mathrm{k}} / \mathrm{HR} 6 \mathrm{~B}$ is dispensable for increased protein catabolism in muscle of fasted mice. Am J Physiol 283: E482-E489

Attaix D, Aurousseau E, Combaret L, Kee A, Larbaud D, Ralliere C, Souweine B, Taillandier D, Tiliganac T (1998) Ubiquitin-proteasome dependent proteolysis in skeletal muscle. Reprod Nutr Dev 38: 153-165 Auboeuf D, Vidal H (1997) The use of the reverse transcriptase competitive polymerase chain reaction to investigate the in vivo regulation of gene expression in small tissue samples. Anal Biochem 245: 141-148

Baracos VE, De Vivo C, Hogle DHR, Goldberg AL (1995) Activation of the ATP-ubiquitin-proteasome pathway in skeletal muscle of cachectic rats bearing a hepatoma. Am J Physiol 268: E996-E1006

Beck SA, Smith KL, Tisdale MJ (1991) Anticachectic and antitumour effect of eicosapentaenoic acid and its effect on protein turnover. Cancer Res 51: $6089-6093$

Beck SA, Tisdale MJ (1987) Production of lipolytic and proteolytic factors by a murine tumour-producing cachexia in the host. Cancer Res 47: $5919-5923$ 
Bodine SC, Latres E, Baumhueter S, Lai VK M, Nunez L, Clarke BA, Poueymirou WT, Panaro FJ, Na E, Dharmarajan K, Pan AQ, Valenzuela DM, DeChiara TM, Stitt TN, Yancopoulos GD, Glass DJ (2001) Identification of protein ligases required for skeletal muscle atrophy. Science 294: 1704-1707

Bossola M, Muscaritoli M, Costelli P, Bellantone R, Pacelli F, Busquets S, Argiles J, Lopez-Soriano FJ, Civello IM, Baccino FM, Fanelli FR, Doglietto GB (2001) Increased muscle ubiquitin mRNA levels in gastric cancer patients. Am J Physiol 280: R1518-R1523

Bossola M, Muscaritoli M, Costelli P, Grieco G, Bonelli G, Pacelli F, Fanelli FR, Doglietto GB, Baccino FM (2003) Increased muscle proteasome activity correlates with disease severity in gastric cancer patients. Ann Surg 237: 384-389

de Blaauv I, Heineman S, Deutz NEP, von Meyenfeldt MF (1997) Increased whole-body protein and glutamine turnover in advanced cancer is not matched by an increased muscle protein and glutamine turnover. J Surg Res 68: $44-55$

Dice JF (1990) Peptide sequences that target cytosolic proteins for lysosomal proteolysis. TPBS 15: 305-309

Emery PW, Edwards RHT, Rennie MJ, Souhami RL, Halliday D (1984) Protein synthesis in muscle measured in vivo in cachectic patients with cancer. BMJ 289: $584-589$

Fearon KCH (1992) The mechanisms and treatment of weight loss in cancer. Proc Nutr Soc 51: 251-265

Fenteany G, Schreiber SL (1998) Lactacystin, proteasome function, and cell fate. J Biol Chem 273: 8545-8548

Galban VD, Evangelista EA, Migliorini RH, Kettelhut IC (2001) Role of ubiquitin-proteasome-dependent proteolytic process in degradation of muscle protein from diabetic rabbits. Mol Cell Biochem 225: 35-41

Gomes MD, Lecker SH, Jagoe RT, Navon A, Goldberg AL (2001) Atrogin-1, a muscle-specific F-box protein highly expressed during muscle atrophy. Proc Natl Acad Sci USA 98: 14440 - 14445

Hasselgren PO, Fischer JE (2001) Muscle cachexia: current concepts of intracellular mechanisms and molecular regulation. Ann Surg 233: 9-17

Jagoe RT, Redfern CPF, Roberts RG, Gibson GJ, Goodship THJ (2002) Skeletal muscle mRNA levels for cathepsin B, but not components for the ubiquitin-proteasome pathway, are increased in patients with lung cancer referred for thoracotomy. Clin Sci 102: 353-361

Kanayama H, Tanaka K, Aki M, Kagawa S, Miyaji H, Satoh M, Okada F, Sato S, Shimbara N, Ichihara A (1991) Changes in expressions of proteasome and ubiquitin genes in human renal cancer cells. Cancer Res 51: $6677-6685$

Khal J, Hine AV, Fearon KCH, Dejong CHC, Tisdale MJ (2005) Increased expression of proteasome subunits in skeletal muscle of cancer patients with weight loss. Int J Biochem Cell Biol in press. Available online

Kisselev AF, Akopian TN, Woo KM, Goldberg AL (1999) The size of peptides generated from protein by mammalian 26 and $20 \mathrm{~S}$ proteasomes. J Biol Chem 274: 3363 -3371

Lecker SH, Solomon V, Mitch WE, Goldberg AL (1999) Muscle protein breakdown and the critical role of the ubiquitin-proteasome pathway in normal and disease states. J Nutr 129: 227S - 237S

Llovera M, Garcia-Martinez C, Agell N, Lopez-Sorino FJ, Argiles JM (1997) TNF can directly induce the expression of ubiquitin-dependent proteolytic system in rat soleus muscles. Biochem Biophys Res Commun 230: $238-241$
Lorite MJ, Smith HJ, Arnold JA, Morris A, Thompson MG, Tisdale MJ (2001) Activation of ATP-ubiquitin-dependent proteolysis in skeletal muscle in vivo and murine myoblasts in vitro by a proteolysis-inducing factor (PIF). Br J Cancer 35: 297-302

Lorite MJ, Thompson MG, Drake JL, Carling G, Tisdale MJ (1998) Mechanism of muscle protein degradation induced by a cancer cachectic factor. Br J Cancer 78: $850-856$

Lovell BB, Ruderman NB, Goodman MN (1986) Evidence that lysosomes are not involved in the degradation of myofibrillar proteins in rat skeletal muscle. Biochem J 234: $237-240$

Medina R, Wing SS, Goldberg AL (1995) Increase in levels of polyubiquitin and proteasome mRNA in skeletal muscle during starvation and denervation atrophy. Biochem J 307: 631-637

O'Keefe SJD, Ogden J, Ramjee G, Rund J (1990) Contribution of elevated protein turnover and anorexia to cachexia in patients with hepatocellular carcinoma. Cancer Res 50: 1226-1233

Orino E, Tanaka K, Tamura T, Sone S, Ogura T, Ichihara A (1991) ATPdependent reversible association of proteasomes with multiple protein components to form $26 \mathrm{~S}$ complexes that degrade ubiquitinated proteins in human HL-60 cells. FEBS Lett 284: 206-210

Rajapurohitam V, Morales CR, El-Alfy M, Lefrancois S, Bedard N, Wing SS (1999) Activation of a UBC4-dependent pathway of ubiquitin conjugation during postnatal development of the rat testis. Dev Biol 212: $217-228$

Shimbara N, Orino E, Sone S, Ogura T, Takashina M, Shono M, Tanura T, Ichihara A (1992) Regulation of gene expression of proteasomes (multiprotease complexes) during growth and differentiation of human haematopoietic cells. J Biol Chem 267: 18100 - 18109

Smith KL, Tisdale MJ (1993a) Increased protein degradation and decreased protein synthesis in skeletal muscle during cancer cachexia. Br J Cancer 67: $680-685$

Smith KL, Tisdale MJ (1993b) Mechanism of muscle protein degradation in cancer cachexia. Br J Cancer 68: 314-318

Temparis S, Asensi M, Taillandier D, Aurousseau E, Larbaud D, Obled A, Bechet D, Ferrara M, Estrella JM, Attaix D (1994) Increased ATPubiquitin-dependent proteolysis in skeletal muscles of tumour-bearing rats. Cancer Res 54: $5568-5573$

Todorov P, Cariuk P, McDevitt T, Coles B, Fearon K, Tisdale M (1996) Characterization of a cancer cachectic factor. Nature 379: 739-742

Waalkes TP, Udenfriend SA (1957) A fluorimetric method for the estimation of tyrosine in plasma and tissues. J Lab Clin Med 50: 733-736

Whitehouse AS, Smith HJ, Drake JL, Tisdale MJ (2001) Mechanism of attenuation of skeletal muscle protein catabolism in cancer cachexia by eicosapentaenoic acid. Cancer Res 61: 3604-3609

Williams A, Sun X, Fischer JE, Hasselgren P-O (1999) The expression of genes in the ubiquitin-proteasome proteolytic pathway is increased in skeletal muscle from patients with cancer. Surgery 126: 744-750

Wing SS, Banville D (1994) 14-kDa ubiquitin-conjugating enzyme. Structure of the rat gene and regulation upon fasting and by insulin. Am J Physiol 267: E39-E48

Workman P, Twentyman P, Balkwill F, Balmain A, Chaplin D, Double J, Embleton J, Newell D, Raymond R, Stables J, Stephens T, Wallace J (1998) United Kingdom Co-ordinating Committee in Cancer Research (UKCCR) guidelines for the welfare of animals in experimental neoplasia (second Edition). Br J Cancer 77: 1 - 10 